\title{
Support after perinatal death: a study of support and counselling after perinatal bereavement
}

\author{
G C FORREST, E STANDISH, J D BAUM
}

\begin{abstract}
After an earlier study into the practical aspects of the management of perinatal death, a counselling service was introduced for parents whose baby had died in the perinatal period. The service was monitored, and the parents who received the service were compared with a group that did not. Fifty families were allocated randomly either to the counselling (supported) group or to the contrast group, who received routine hospital care. Assessment was carried out at six and 14 months after the death, using a semi-structured interview and two selfrating scales (the general health questionnaire and the Leeds scales). Two of 16 mothers in the supported group showed psychiatric disorder at six months, compared with 10 of 19 in the contrast group $(p<0.01$, Fisher's exact test). There was no significant difference between the two groups at 14 months, when $80 \%$ of all the women studied had recovered from psychiatric symptoms. Socially isolated women and those whose marital relations lacked intimacy had a higher incidence of psychiatric symptoms at six months. Early pregnancy (within six months) was associated with a higher incidence of
\end{abstract}

\footnotetext{
The Park Hospital for Children, Old Road, Headington, Oxford OX3 7LQ

G C FORREST, MB, MRCPSYCH, senior registrar (present appointment: consultant in child psychiatry)

E STANDISH, BA, research assistant (present appointment: psychiatric social worker, Abingdon Child Guidance Clinic, Faringdon Road, Abingdon)

University of Oxford Medical School, John Radcliffe Hospital, Oxford

J D BAUM, MD, FRCP, clinical reader in paediatrics
}

psychiatric symptoms in the unsupported group. The duration of bereavement reaction after perinatal death was appreciably shortened by support and counselling.

\section{Introduction}

In the United Kingdom about one in 70 babies dies at or around $\overrightarrow{\overrightarrow{0}}$ the time of birth. ${ }^{1}$ Despite the frequency of this event (1403 times commoner than phenylketonuria and nearly 50 times commoner than congenital hypothyroidism ${ }^{2}$ ), only in the last 10 . years has the family's reactions to the loss of the baby and the management of their emotional needs received the attention of obstetricians, paediatricians, and psychiatrists. Although many:anecdotal accounts have been published, ${ }^{34}$ few systematic 3 . studies have been undertaken. Giles, ${ }^{5}$ in one of the first studies,, interviewed 40 bereaved women within a few days of their baby's 3 neonatal death, and described their emotional and physicalo reactions. These were similar to the grief reactions described by Parkes $^{6}$ and by Lindemann ${ }^{7}$ that follow the loss of any loved ज person. Wolff et $a^{8}$ followed up for three years 50 women who had had a stillbirth. All but two, who were already being treated for a psychiatric disorder, showed typical grief reactions. 0 Half of the women seemed to have coped with their loss by N becoming pregnant again, while the other half had returned to work or intensified their normal activities. In their study of 250 women who had lost a newborn baby Jensen and Zahourek ${ }^{\circ} \frac{\mathrm{C}}{\Phi}$

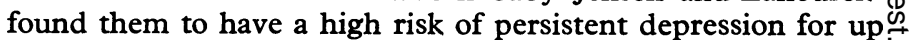
to one year after the death.

Two different approaches have been developed to try to improve the care of these families and thereby prevent the atypical grief reactions ${ }^{10}$ or prolonged emotional disturbance $\stackrel{\vec{Q}}{\Omega}$ that may follow perinatal bereavement. The first approach consists of recommendations for the practical management of the stillbirth or neonatal death, produced by the Nationalo Stillbirth Study Group in 1978. ${ }^{11}$ These include encouraging 
parents to see and name the baby, hold a funeral, make opportunities for discussions with the medical staff, and obtain obstetric and genetic counselling. The second approach is to provide families with some form of bereavement counselling, either by professionals or by self-help groups, such as the Compassionate Friends or the Stillbirth and Perinatal Death Association. Although bereavement counselling has been practised for many years, particularly with widows, there is still uncertainty about its effectiveness. There have been few controlled studies of counselling. Nevertheless, Parkes ${ }^{12}$ has concluded that bereavement counselling services "are capable of reducing the risk of psychiatric and psychosomatic disorders resulting from bereavement." We therefore decided to test the hypothesis that psychological recovery from stillbirth or early neonatal death (death of the baby within the first seven days after birth) is enhanced by a planned programme of support and counselling.

\section{Method}

The study was a randomised trial carried out in the John Radcliffe Maternity Hospital in Oxford. Fifty unselected mothers of babies over 28 weeks' gestation were recruited over an 18 -month period. Twenty-five were mothers of stillborn infants and 25 of babies who had died in the newborn period. Mothers of babies or fetuses of 28 weeks' gestation or more were chosen because of the changes in administrative procedures for dealing with the body after this point, and not because it was thought that parents of babies under that gestational age suffer differently. Immediately after the death or stillbirth of their baby, the mothers were randomly allocated either to a group that received planned support and counselling or to a contrast group that received routine hospital care.

The supported group was guaranteed the comprehensive application of the recommended proposals for "ideal" care. They were all encouraged to see, hold, and name their dead baby; a photograph of the baby was taken and kept; the mother was given the choice, whenever possible, of returning to her own ward or to the isolation floor; and discharge was not hurried, allowing time for contact with the medical staff, social worker, community midwife, and general practitioner. Bereavement counselling was offered to both parents between 24 and 48 hours after the baby's death. The follow-up arrangements were planned to ensure that parents received obstetric counselling from their obstetrician, genetic counselling if necessary, and an opportunity to discuss the postmortem results with a paediatrician. The contrast group had a wide variety of care, which depended on several factors, including the attitude of individual staff members and the parents' own reactions to their loss. The minimum care (which applied in few cases) consisted of no opportunity to see the baby; automatic placement in a single room on the isolation floor; discharge home within 24 hours; and no hospital follow-up.

\section{EVALUATION}

Both the supported group and the contrast group were assessed six and 14 months after the baby's death. The families'general practitioners were first asked for permission to proceed; then a letter was sent to the parents asking for their co-operation with the study. The evaluation took place in the parents' home and was carried out by a trained interviewer who did not know to which group the family had been allocated. A semi-structured interview was used, based on the work of Parkes and Brown. ${ }^{13}$ In addition, the parents were asked to complete two standardised self-rating scales to measure psychiatric disorderthe general health questionnaire ${ }^{14}$ to give a general assessment of the presence of psychiatric disorder and the Leeds scales ${ }^{15}$ to give more specific information about the presence of depression and anxiety.

\section{COUNSELLING}

The first interview was offered to both parents in the supported group before they left hospital-usually between 24 and 48 hours after the baby's death. If one of the medical social workers already knew the family she offered this counselling. Otherwise, one of the midwives would offer the parents an interview with a family psychiatrist (GCF). Twenty parents $(80 \%)$ accepted this offer; and the fathers seemed pleased to be included. For most families this was their first experience of bereavement-and it must be remembered that this bereavement was sudden and unexpected-and they welcomed help with mourning. The aims of the first interview were to establish rapport with the parents; assess their personal resources for coping with their loss; define their supportive network at home; help create real memories of the baby; and facilitate the expression of emotion. A thorough knowledge of the registration procedures and funeral arrangements helped to establish rapport. ${ }^{16}$

Further counselling was offered until it was thought that the parents were well established in their mourning and well supported in their neighbourhood. For most couples this took two to six weeks; for four, it required longer-up to eight sessions spanning four months (fig 1).

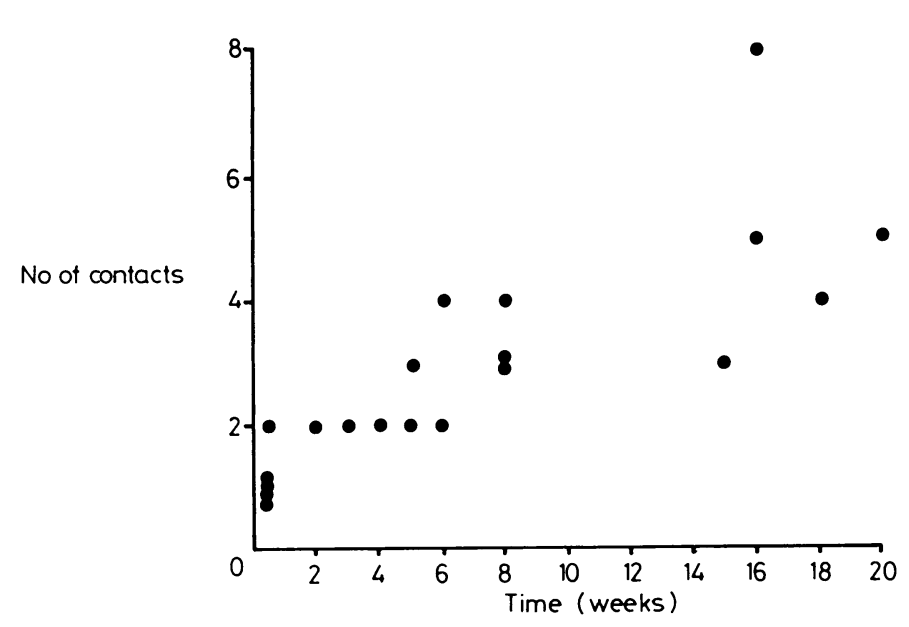

FIG 1-Bereavement counselling: number of contacts made with each family in the supported group over a period.

Since the duration of treatment necessarily varied, clearly no predetermined course of counselling sessions meets the need of these parents. Indeed, in two cases normal mourning was never successfully achieved.

\section{PATIENTS}

The mean age of the mothers was 27 (range 18-40) and the fathers 30 (range 21-49). Forty-nine couples were married and one couple was cohabiting. There was a preponderance of social classes II and III, consistent with the bias of the Oxford maternity unit population (unpublished observations). There were three Asian families, one African, and one Japanese; the remaining 45 families were Caucasian.

For 18 women this was their first pregnancy, 24 already had living children, and eight had previously had miscarriages only. Six had had a stillbirth or an infant death. Two had been sterilised immediately after delivery and before their babies had died.

There were 20 boys and 30 girls; 48 were singletons and two were twins. Twelve were delivered by caesarean section, the rest vaginally. Thirteen babies were macerated stillbirths while 13 died of congenital malformations, nine of immaturity, and 10 of "asphyxia" during labour or delivery. There were five others with miscellaneous specific causes -for instance, rhesus incompatibility. The supported and contrast groups were comparable on all these parameters.

\section{Results}

Sixteen of the supported group and 19 of the contrast group were interviewed at six months (compliance rate $70 \%$ ). Ten declined to take part; the general practitioners of another four did not wish their patients to be contacted "for fear of upsetting them"; and one couple had left the country. Some information relating to these 15 women was collected from their general practitioners. The interviews took between one and two hours, and, although husbands were invited, 
only six attended. Twenty-six husbands, however, completed the self-rating scales and posted them a few days later.

All the mothers interviewed had experienced typical bereavement symptoms: tearfulness, sadness, lethargy, insomnia, and physical manifestations of anxiety, such as palpitations, guilt, and irritability. All these symptoms tended to intensify in bouts-the "pangs" of grief. They had all searched for a cause of their baby's death, and most had experienced angry feelings in the first month or so.

\section{SELF-RATING SCALES}

The standard cut-off point for psychiatric disorder with the 60 item general health questionnaire is a score of $12+$. At six months, two of the 16 supported mothers compared with 10 of the 19 contrast mothers scored $12+$ on the general health questionnaire, indicating a lower rate of psychiatric disorder in the supported group $(p<0.01$, Fisher's exact test). When the scaled version of the general health questionnaire was examined ${ }^{17}$ anxiety, somatic symptoms, and impairment of social functioning were as common as depressive symptoms in the high scorers. This draws attention to the need to consider symptoms other than those of depression. Three particular symptoms were experienced by the high scorers: a preoccupation with thoughts of the dead baby, frequent feelings of numbness, and difficulty in accepting that the baby was dead.

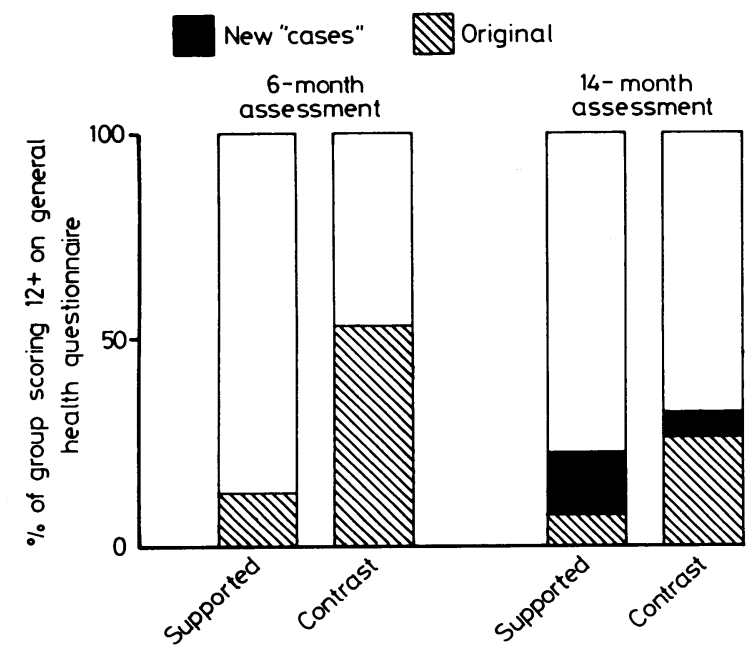

FIG 2-Progress of the groups: incidence of psychiatric disorder in each group at the six-month and 14-month assessments (general health questionnaire).

With the Leeds scales the standard cut-off score of seven was used to delineate pronounced symptoms of depression and anxiety. At six months, five of the 16 supported group compared with 12 of the 19 contrast group scored $7+$ on either the Leeds anxiety scale or on both the anxiety and depression scales $(p=0.06)$. No woman scored $7+$ on the depression scale alone. The two women who had been sterilised were both high scorers. There was no statistically significant difference in incidence of high scores after stillbirth compared with neonatal death.

At 14 months four women declined to be interviewed a second time, stating that they thought nothing had changed. One woman who had moved abroad could not be traced. Thus 30 women were interviewed. The results of the general health questionnaire at this time showed no statistically significant difference between the supported and contrast group. Half of the women in both groups who had had scores of $12+$ at six months were now scoring below 11: one of the 12 supported women compared with four of the 18 in the contrast group remained ill. There were two new "high scorers" in the supported group and one in the control group-two of these were associated with the birth of another baby, one from each group (fig 2).

The Leeds scales showed a similar fall in anxiety or anxiety plus depression. Again there was no significant difference between the supported and contrast groups. The two women who had been sterilised continued to be high scorers at 14 months.

\section{PREGNANCIES}

One mother put it like this: "All you want after an experience like this is to have another baby. There is such a gap, it has to be filled."

By six months, $16(32 \%)$ of the 49 women in the study had become pregnant, including three who miscarried later. By 14 months, this figure had risen to $28(56 \%)$. During the study 11 women delivered live babies. The incidence of pregnancies in the supported group and the contrast group was similar at both six and 14 months despite the fact that the women in the supported group had been advised to wait until they thought that they had recovered from the loss of the baby. There seemed to be a difference in the association between psychiatric disorder and pregnancy in the two groups. At six months, of the 35 women interviewed, 11 were pregnant-three of the 16 supported group and eight of the 19 contrast group. None of the three pregnant women in the supported group was showing psychiatric disorder (as measured by the general health questionnaire) compared with six of the eight pregnant women in the contrast group $(p=0.06$, Fisher's exact test). At 14 months seven of the interviewed group were pregnant. This time, only one of the five pregnant women in the contrast group was showing psychiatric disorder compared with one of the two supported women.

\section{NEW BABIES}

By 14 months seven (three supported and four contrast) of the 35 women interviewed had new babies, aged between 4 weeks and 6 months. Five of the women were considered to be relating normally to their babies, but two (one supported, one contrast) were experiencing negative feelings and seemed unresponsive to the baby during interview. The ambivalent feelings of one of these mothers were attributed to her enforced eight-week separation from her new baby while he was cared for in a special care baby unit 50 miles away.

EFFECTS ON THE FAMILIES

\section{Other children}

Twenty-two of the 35 women interviewed had other children at home. These 32 children ranged in age from 14 months to 14 years, though 16 were under 5 . All the mothers reported becoming more protective towards their children. Particular difficulties were reported with those aged 3 and 4. One 4-year-old, whose parents had become depressed, irritable, and withdrawn during the first six months, told them: "No one loves me in this house any more except my baby sister, and she's gone to live with Jesus." Another child, aged 3, was obviously bewildered by her mother's grief, and kept asking, "Why is Mummy sad ? Is it the baby ? What did I do wrong, hurt the baby, so it went away ?" For older school-age children, there was the problem of their schoolfriends' inquisitive questions. One 6-year-old had rushed home from school in tears of indignation, saying to her mother, "I have got a baby sister, haven't I ? Even if she is with God ?"

The children's grief reactions were mostly brief, except where the mothers remained severely depressed and anxious for many months. Their bereavement symptoms included naughtiness and overactivity as well as anxiety and sadness.

\section{Marriage}

Half the women interviewed stated that the loss of the baby had improved their relations with their husbands; the other half stated that their relations had been unaffected by the bereavement. But three of the 50 couples separated within the first six months (two contrast and one supported). Apparently the loss of the baby precipitated marital breakdown.

One case (in the contrast group) illustrates the disastrous sequence of events that may overtake a couple. A newly married couple lost their first baby. He was born at 29 weeks' gestation and died 12 hours later. The husband took to heavy drinking immediately and stopped visiting his wife in the maternity unit. Shortly afterwards he was sacked from his job but continued drinking. His wife left him eight weeks later, already pregnant, and returned to live with her parents. She found their constant criticism of her husband intolerable and a month later she moved into a bedsitter on her own. When she was interviewed at six months, she was depressed and anxious, and had a general health questionnaire score of 14 . She subsequently delivered 
a healthy baby girl but totally rejected her. At the 14-months' assessment, the husband, now sober, was looking after the baby while the mother was severely depressed, suicidal, and living alone. Her general health questionnaire score was 47 (one of the highest scores in the study).

\section{Fathers}

Since only six fathers attended the first assessment interview (three supported and three contrast), it was not possible to gather detailed information about their experiences of losing their baby. It seemed from the mothers' accounts that most fathers had coped in the early weeks by plunging themselves into their work as soon as possible.

Fourteen fathers in the contrast group and 12 supported fathers completed the self-rating scales. There were no significant differences between the two groups on either the general health questionnaire or the Leeds scales at six months (two of the supported group scored $12+$ on the general health questionnaire compared with two of the contrast group). On the Leeds scales, like the mothers, no fathers scored $7+$ on the depression scale alone-two of the 12 supported compared with two of the 14 contrast group scored $7+$ on the anxiety scale or both anxiety and depression scales. The two high-scoring supported fathers had recovered at 14 months: the two fathers in the contrast group remained high scorers.

The striking thing about the fathers' general health questionnaire results was the lower incidence of high scorers in the contrast group at six months compared with mothers in the contrast group (two of 14 fathers compared with 10 of 19 mothers, $p<0.03$ ), and the frequency with which the fathers scored " 0 " on the general health questionnaire at six months compared with the mothers (12 of 26 compared with 6 of 35, p <0.05).

\section{“AT RISK” FACTORS}

To try to identify "at-risk" factors in the women several factors were studied retrospectively in the contrast group, where they would be uncontaminated by the effects of counselling, and their association with high scores in the general health questionnaire at six months was assessed. Infertility, low social class, previous psychiatric illness, children under 14 at home, caesarean section, stillbirth, and no previous bereavement were not found to be statistically significant.

The only statistically significant associations with a high score were social isolation $(p<0.04)$ and poor relations (low intimacy) with husband $(\mathrm{p}<0.02)$.

The mother was rated as socially isolated if she could not name anyone among her family or acquaintances whom she perceived as supportive. The marital relations were rated low in intimacy if the mother reported an inability to share or discuss emotionally charged topics with her husband.

\section{MOTHERS' COMMENTS ON THEIR CARE ${ }^{18}$}

For some women the first assessment interview was clearly a muchneeded opportunity to talk about their baby's death and the effects of this on them and their family. They recalled with great clarity the events surrounding the death, and commented particularly on hurtful remarks, such as that made by one doctor when he had asked the mother how she wanted her baby "disposed of."

At the end of the interviews, the mothers were asked to comment on the care received in hospital or at home. Only one said that she would not go back to the same unit to have another baby. Nearly half, however, thought that their care could have been improved. Most comments concerned communications with medical staff. Most mothers did not blame their doctors for their baby's death, nor did they expect their doctors to say something to make them feel better. They wanted them to explain in simple language what had gone wrong, and then to listen and accept their distress. Some had found lack of sympathy or understanding of their predicament among the staff upsetting - for instance, the technician who had prevented one father accompanying his wife while she had a scan to confirm the intrauterine death of their baby, saying, "It's not a peep show, you know."

Lack of communication between staff was another source of distress. The day after one woman's baby boy died, a midwife came in and inquired when they were going to deliver her; two weeks after her discharge home the health visitor arrived "to check on the baby," and, finally, after sending a small sum of money to the special care baby unit the couple had received a note thanking them for their donation and sending "best wishes to your little boy."

Flexibility had been important where mothers had thought that their care had been good-for example, where they had been encouraged to choose the type of funeral they wanted. The photographs of the dead babies taken for the supported group proved to be of value mainly to those parents who had declined to see their baby at delivery and who had regretted this later. Most parents who actually saw and held their babies preferred to keep this memory of the baby rather than a photograph. Twelve mothers held strong religious beliefs and had been helped by visits from their own ministers or the hospital chaplain.

\section{MOTHERS' EARLY REACTIONS}

The bereavement reactions observed were all normal in form, although their duration varied. Feelings of shock and numbness were almost universally described by parents in the first 24 hours. The absence of any expressed emotion at this time was sometimes interpreted by the staff as "coping well." After a few days, parents then began desperately seeking an explanation for their baby's death and had begun to express anger or guilt about events in their pregnancy and labour. As one woman put it "I feel so cheated. All that for nothing. I am so empty." The mothers expressed their emotions more freely than the fathers, many of whom felt obliged to be "strong" and controlled. Often parents were anxious about what to say to their young children when they got home.

Parents often found that relations with friends and acquaintances were difficult in the first few weeks: friends with young children tended to keep away at first, and then perhaps a month or so later assumed that the parents had recovered. Fathers often found that their colleagues at work never mentioned the baby's death, though they tried to be generally supportive by, for example, reducing his work load for a short time. Few parents anticipated the need that most bereaved people experience over several weeks, of repeatedly reviewing the events surrounding the baby's death. They thought that this "bored" their friends and many withdrew socially in the second month.

\section{Discussion}

Bereavement reactions should not be regarded as psychiatric disorders necessarily requiring treatment, but the people experiencing them may need medical intervention. The relevance of the high scores on the self-rating scales is the indication they give of delayed recovery from the psychological symptoms associated with bereavement. The results of the study suggest that the impact of the programme of support and counselling in the early months of bereavement appreciably shortened the duration of bereavement reaction for the mothers in the supported group. There is little information available yet on the normal duration of bereavement reactions after perinatal death. Nevertheless, the contrast group may be taken to represent the natural history of bereavement reactions after stillbirth or early neonatal death. Half of these women showed appreciable symptoms of depression and anxiety at six months and $20 \%$ at 14 months (general health questionnaire). In other words, $80 \%$ of them had recovered from their grief by 14 months. By contrast, fathers recovered more rapidly- $86 \%$ by six months.

Women were not ready by six months to cope with the emotional stress of another pregnancy without support and counselling. By 14 months, however, they had recovered sufficiently with or without support and counselling.

Two "at-risk" factors were identified retrospectively-a lack of supportiveness in a woman's relations with her friends and neighbours, and poor relations (low intimacy) with her husband. Raphael $^{19}$ studied a group of 200 Australian widows and identified several factors that seemed to increase their vulnerability to atypical or prolonged grief reactions. She subsequently tested the validity of these factors in a controlled trial of bereavement counselling for selected widows, and established that the 
most significant was the absence of a (perceived) supportive network. The assessment of these sorts of factors retrospectively is not satisfactory, as a mother's account of her friends' and her husband's behaviour is likely to be influenced by her state of mind. But our results are similar to Raphael's and indicate the need for further research to identify those women, and their husbands, most at risk for prolonged bereavement reactions.

\section{PRACTICAL IMPLICATIONS}

Several practical implications for the staff of a maternity unit have emerged.

(1) There was evidence of the beneficial effects of a combination of the type of supportive care recommended by the National Stillbirth Study Group together with bereavement counselling. The counselling was required for only six to eight weeks by $75 \%$ of the mothers seen, which suggests that the medical social workers attached to maternity units could undertake this task. Specialists, such as psychiatrists or bereavement counsellors, will be needed for a few parents, and this "at-risk" group should be identified as soon as possible so that extra support may be mobilised for them. Until further research has clarified at-risk factors, all bereaved women should have their home circumstances assessed before they are discharged from the maternity unit.

(2) Opportunities for discussion with medical staff about what went wrong with the pregnancy and about worries for future pregnancies are important. Parents did not expect hours of their busy obstetrician's or paediatrician's time. A short meeting before discharge, and an appointment for a second meeting lasting about 15 to 30 minutes with a senior doctor during the first month was greatly appreciated. Naturally, mothers who have lost a baby will require advice and support through their next pregnancy.

(3) All the parents interviewed had found it difficult to give consent for a necropsy but did so in the hope that the information provided would help to clarify what had gone wrong. The result of the necropsy was seen, therefore, to be important to them; they expected the results to be discussed with them when they returned to the hospital. The family's general practitioner does not on the whole have the specialist knowledge necessary to discuss this information and its implications.

(4) Support for parents after discharge may be provided from several sources including the Stillbirth and Perinatal Death Association, medical social workers, and community-based professionals. Parents greatly valued early contact with their own general practitioner (before they left hospital if possible; otherwise as soon as they got home) and also with the community midwife who had provided antenatal care. Good communication between the professionals in the hospital and the community is obviously a prerequisite for providing support at the earliest opportunity.

(5) The women in the contrast group seemed to cope better psychologically with their next pregnancy if they had waited more than six months before conceiving. It would seem appropriate to advise bereaved parents to wait a few months, rather than urge them to get pregnant again immediately.

(6) There are obvious implications from this study for the training of student midwives, obstetricians, paediatricians, and staff in special care baby units. All too often, training programmes emphasise the technical rather than the psychological aspects of management. This leaves the student without the skills necessary to cope with his patients' and his own reactions to death. As a result junior medical and nursing staff tend to withdraw from a position where, with a little basic training, they could be both humane and actively helpful.

This research was supported by a grant from the Oxford Region Locally Organised Research Fund. We thank the parents who participated in the study, the staff of the maternity unit of the John Radcliffe Hospital, colleagues in the University Department of
Psychiatry, Oxford, for their help in the design of the study and preparation of the manuscript, and Mrs Linda Pollock and Mrs Nancy Thomas for the typing.

\section{References}

1 Office of Population Censuses and Surveys. 1980 statistics. London: HMSO, 1981.

2 Department of Health and Social Security. Screening for early detection of congenital hypothyroidism. HN(81)20. London: DHSS, 1981.

${ }^{3}$ Cooper JD. Parental reactions to stillbirth. British fournal of Social Work 1980;10:55-69.

4 Lewis E. Reactions to stillbirth. In: Psychosomatic medicine in obstetrics and gynaecology. 3rd International Congress, Basel. London: Karger, 1971: 323-5.

${ }^{5}$ Giles P. Reactions of women to perinatal death. Aust NZ $\mathcal{Y}$ Obstet Gynaecol 1970;10:207-10.

6 Parkes CM. The effects of bereavement on physical and mental health. Br Med F 1964 ;ii:274.

${ }^{7}$ Lindemann E. Symptomatology and management of acute grief. $A m \mathcal{F}$ Psychiatry 1944;101:141-8.

${ }^{8}$ Wolff JR, Nielson PE, Schiller P. The emotional reaction to a stillbirth. Am $\mathcal{F}$ Obstet Gynecol 1970;108:73-7.

9 Jensen JS, Zahourek R. Depression in mothers who have lost a newborn. Rocky Mountain Medical fournal 1972;71:61-3.

${ }^{10}$ Lewis E, Page A. Failure to mourn a stillbirth-an overlooked catastrophe. Br $\mathcal{F}$ Med Psychol 1978;51:237-41.

11 Health Education Council, National Association for Mental Health, and the National Stillbirth Study Group. The loss of your baby. London: HEC, 1979.

12 Parkes CM. Bereavement counselling-does it work? $\mathrm{Br}$ Med $\mathcal{F} 1980$; $281: 3-6$.

13 Parkes CM, Brown RJ. Health after bereavement, a controlled study of $\mathrm{N}$ young Boston widows and widowers. Psychosom Med 1972;34:449-61.

14 Goldberg DP. The detection of psychiatric illness by questionnaire. Oxford: Oxford University Press, 1972.

15 Snaith RP, Bridge GW, Hamilton A. The Leeds scales for the selfassessment of anxiety and depression. Br F Psychiatry 1976;128:156-65

${ }_{16}$ Forrest GC, Claridge R, Baum JD. The practical management of perinatal death. $B r$ Med F $1981 ; 282: 31-2$.

17 Goldberg DP, Hillier VF. A scaled version of the general health questionnaire. Psychol Med 1979;9:139-45.

${ }^{18}$ Standish E. The loss of a baby. Lancet 1982;i :611-2.

19 Raphael B. Preventive intervention with the recently bereaved. Arch Gen Psychiatry 1977;34:1450-4.

(Accepted 9 September 1982)

Roughly what blood alcohol concentration would be produced in a healthy middle-aged woman by $300 \mathrm{ml}$ of Dry Martini $(17 \% \mathrm{vol})$ one and $a$ half hours after its ingestion and 12 hours after the last meal? Would disulfiram (Antabuse) affect the blood alcohol level or the analysis ?

Any attempt to forecast peak blood alcohol concentration from the ingestion of any given amount of drink is fraught with inaccuracies. Different people have very different responses and even the same person will produce a different peak under different circumstances. Though in this case there would be no complication from food in the stomach, there are still many imponderables which make such a calculation merely a rough estimate. One factor would be the degree of habituation to alcohol, which acts both by a possible chronic gastritis reducing absorption rate and the possibility of the rapidity of liver metabolism being increased in the earlier stages of habituation, but considerably decreased when alcoholic liver failure ensues. Three hundred millilitres of vermouth (17\% volume) means an alcohol load of about $40 \mathrm{~g}$. Assuming the weight to be in the region of $60 \mathrm{~kg}$ this (on a very approximate basis) would suggest a peak alcohol concentration of $80-100 \mathrm{mg} / 100 \mathrm{ml}$ of blood. On a completely empty stomach, this would peak early, perhaps between half an hour and one hour, especially as the concentration of alcohol in the ingested fluid would be almost the optimum for rapid absorption. Probably, therefore, by one and a half hours the level would have begun to drop from the peak, the usual rate of fall being $10-20 \mathrm{mg} / 100 \mathrm{ml} / \mathrm{h}$. The concentration is likely therefore to be in the region of $60-80 \mathrm{mg} /$ $100 \mathrm{ml}$, but it must again be emphasised that there are great variations in either direction, especially in habituated drinkers. The presence of disulfiram would not affect either the blood level or the analysis. BERNARD KNIGHT, professor of forensic pathology, Cardiff. 